\title{
Treatment with an aldose reductase inhibitor can reduce the susceptibility of fast axonal transport following nerve compression in the streptozotocin-diabetic rat
}

\author{
L. B. Dahlin*, D. R. Archer and W.G. McLean \\ Department of Pharmacology and Therapeutics, University of Liverpool, Liverpool, UK
}

\begin{abstract}
Summary. The effect of treatment with an aldose reductase inhibitor on the susceptibility of peripheral nerves to compression was studied in rats made diabetic by the injection of streptozotocin $\left(50 \mathrm{mg} \cdot \mathrm{kg}^{-1}\right)$. The response to nerve compression was determined in untreated diabetic rats after 22 days of diabetes and compared with the response in two similar groups of diabetic rats which had been treated with the aldose reductase inhibitor 'Statil' (ICI 128436; $25 \mathrm{mg} \cdot \mathrm{kg}^{-1}$. day $^{-1}$ orally) either from the induction of diabetes or for 7 days prior to nerve compression. Two groups of non-diabetic rats were treated with 'Statil' for either 22 days or 7 days to act as controls. Inhibition of fast axonally transported proteins was induced by local compression of the sciatic nerves $4 \mathrm{~h}$ after application of ${ }^{3} \mathrm{H}$-leucine to the motor neurone cell bodies in the spinal cord. The inhibition of fast axonal transport was quantified by calculation of a transport block ratio.

Compression at $30 \mathrm{mmHg}$ for $3 \mathrm{~h}$ induced a significantly greater $(p<0.05)$ inhibition of axonal transport at the site of compression in nerves of untreated diabetic rats (transport
\end{abstract}

block ratio $0.96 \pm 0.24, n=8$ ) than in nerves of control rats treated with the aldose reductase inhibitor for either the shorter time of 7 days $(0.71 \pm 0.17, n=10)$ or the longer time of 22 days $(0.69 \pm 0.08, n=5)$. In diabetic rats treated with the aldose reductase inhibitor for 22 days the inhibition $(0.77 \pm 0.12, n=6)$ was significantly less than that in untreated diabetic rats; treatment for 7 days reduced the transport block ratio to $0.85 \pm 0.11(n=8)$, but the effect was not significant. Treatment for 22 days prevented the marked increase in nerve sorbitol found in the diabetic rats but did not prevent a fall in nerve myo-inositol. The results indicate that treatment with an aldose reductase inhibitor for a sufficient period of time can reduce the increased susceptibility of peripheral nerves to compression in streptozotocin-induced diabetes mellitus in the rat by a mechanism which may be related to the prevention of increases in sorbitol in the nerves.

Key words: Aldose reductase inhibitor, streptozotocin, axonal transport, compression syndromes, diabetes mellitus, mononeuropathy, sorbitol, myo-inositol.
The peripheral nerves of the upper and lower extremity can become spontaneously compressed at different locations along their course in the limb. The most common syndrome in the upper extremity is the carpal tunnel syndrome where the median nerve is compressed in the carpal tunnel at the wrist. One of the diseases associated with carpal tunnel syndrome is diabetes mellitus and clinical studies have suggested that there is an increased susceptibility of peripheral nerves to trauma in that condition [1-5]. The clinical observations have been confirmed by experimental studies [6-9]. It is not known which factors are important for this increased susceptibility, but increased water content as a consequence of elevated levels of nerve sorbitol may be of

* Present address: Laboratory of Experimental Biology, Department of Anatomy, University of Göteborg, Göteborg, Sweden importance [9-11]. The present study was performed in order to investigate that possibility by treatment of the rats with an aldose reductase inhibitor (ARI), which reduces the accumulation of sorbitol and fructose in the nerve [9-12].

\section{Materials and methods}

\section{Induction of diabetes}

Weight-matched female Wistar rats, 11-14 weeks of age and weighing $170-250 \mathrm{~g}$, were divided into five groups. Diabetes was induced in three groups with a single intravenous or intraperitoneal injection of streptozotocin (STZ; $50 \mathrm{mg} / \mathrm{kg}$ ) dissolved in $0.01 \mathrm{~mol} / 1$ citrate buffer, $\mathrm{pH} 4-4.5$, in the same way as previously described $[9,15]$. Two other groups of animals received an equivalent volume of citrate buffer (controls). Diabetic rats received no insulin. Fasted 
whole blood glucose was measured with glucose-sensitive reagent sticks in an Ames Glucochek at regular intervals after the STZ-injection. Only animals with whole blood glucose values above $14.0 \mathrm{mmol} / \mathrm{l}$ were included in the diabetic groups.

\section{Experimental groups}

The aldose reductase inhibitor, 'Statil' ICI 128436 [3-(4-bromo-1-fluorobenzyl)-4-oxo-3 $H$ phthalazin-1-yl-acetic acid] was administered once daily orally by gavage at a dose of $25 \mathrm{mg} / \mathrm{kg}$. 'Statil' is a trademark, the property of Imperial Chemical Industries PLC. Five groups of rats were established: (A) control rats treated with 'Statil' for 22 days; (B) control rats treated with 'Statil' for 7 days; (C) agematched diabetic rats treated with 'Statil' from induction of diabetes; (D) age-matched diabetic rats treated with 'Statil' from Day 15 after streptozotocin for a further 7 days; (E) age-matched untreated diabetic rats.

\section{Axonal transport}

After 22 days of diabetes, the rats were anaesthetized with pentobarbital (Sagatal ${ }^{\mathbb{N}} ; 60 \mathrm{mg} / \mathrm{ml}$ intraperitoneally) and the $\mathrm{L}_{4}$ and $\mathrm{L}_{-5}$ spinal cord segments were exposed by a laminectomy of the $L_{1}$ and $\mathbf{L}_{2}$ vertebrae as previously described $[9,15]$. One hundred $\mu \mathrm{Ci}$ of $\mathrm{L}$ $[4,5]{ }^{3} \mathrm{H}$-leucine (specific activity $124 \mathrm{Ci} / \mathrm{mmol}$; Amersham, UK) were injected into the area of the motor neurone cell bodies through a glass micro-pipette according to the method described previously $[9,15]$. Four to eight injections (total around $3 \mu \mathrm{l}$ ) were made into the left side of the spinal cord each time. The wound was sutured and animals were placed on insulating cushions under a heating lamp in order to keep body temperature constant at $37^{\circ}-38^{\circ} \mathrm{C}$. During anaesthesia intraperitoneal injections of isotonic saline were given to the diabetic rats to avoid dehydration (total $20-25 \mathrm{ml} / \mathrm{rat}$ ).

\section{Compression procedure}

Four hours after the spinal cord injection, the left sciatic nerve was exposed in the thigh, with the rats again under anaesthesia. The nerve was carefully dissected free and a small compression chamber, consisting of two rubber membranes encased in perspex [9] was applied around the nerve trunk. The chamber was inflated with nitrogen to a pressure of $30 \mathrm{mmHg}$ which was maintained for $3 \mathrm{~h}$. The application of the chamber per se is known not to induce any inhibition of fast axonal transport $[9,16]$.

\section{Determination of radioactivity}

Three hours after application of the chamber the animals were killed and the sciatic nerve quickly dissected out and frozen. A loose suture was placed around the nerve to indicate the position of the proximal edge of the compressed segment. Each nerve was cut into $2.5 \mathrm{~mm}$ pieces and the pieces were soaked individually in $2 \mathrm{ml}$ of cold $10 \%$ trichloroacetic acid overnight at $+4^{\circ} \mathrm{C}$. The pieces were then washed once in a further $2 \mathrm{ml}$ cold trichloroacetic acid and dissolved in $0.3 \mathrm{ml}$ of Protosol ${ }^{\circledR}$ (New England Nuclear, Boston, Mass, USA) or $0.25 \mathrm{ml}$ Optisolv either for $1 \mathrm{~h}$ at $55^{\circ}$ or overnight at room temperature. Two ml of toluene-based scintillation fluid were added to each dissolved nerve piece and the radioactivity of each sample was measured in a liquid scintillation counter with automatic quench correction.

\section{Determination of sorbitol and myoinositol}

Sorbitol and myo-inositol were measured in the contralateral nerve by Gas-Liquid Chromatography according to the method of Stribling et al. [17] and expressed in terms of wet weight of nerve.

\section{Statistical analysis}

A ratio - the transport block ratio - reflecting the accumulation of transported radioactive proteins around the proximal edge of the compressed segment was calculated in the same way as previously described [9]. In short, the radioactivity in three nerve pieces (two pieces in the proximal part of the compressed area and one piece immediately proximal to the compressed area) was expressed as a fraction of the radioactivity contained in six pieces proximal to the above mentioned three pieces. Data were analysed for homogeneity of variance by the Bartlett-Box test and then by one-way analysis of variance. As our main interest lay a priori in the difference between untreated diabetic rats and diabetic rats treated with ARI, significance was calculated by least significant difference [18]. P-values < 0.05 were considered significant (two tail). The values are presented as mean $\pm \mathrm{SD}$, with $95 \%$ confidence limits where appropriate. Statistical comparison of nerve sorbitol and myo-inositol levels was by Student's t-test.

\section{Results}

\section{Body weight and blood glucose}

The changes in body weight and whole blood glucose levels during the experimental period are shown for all groups of rats in Table 1. The diabetic rats had whole blood glucose levels above $14 \mathrm{mmol} / 1$, polyuria, polydipsia and weight loss; treatment with the ARI did not prevent weight loss or affect severity of diabetes.

Table 1. Changes in body weight and blood glucose concentration for all groups of rats

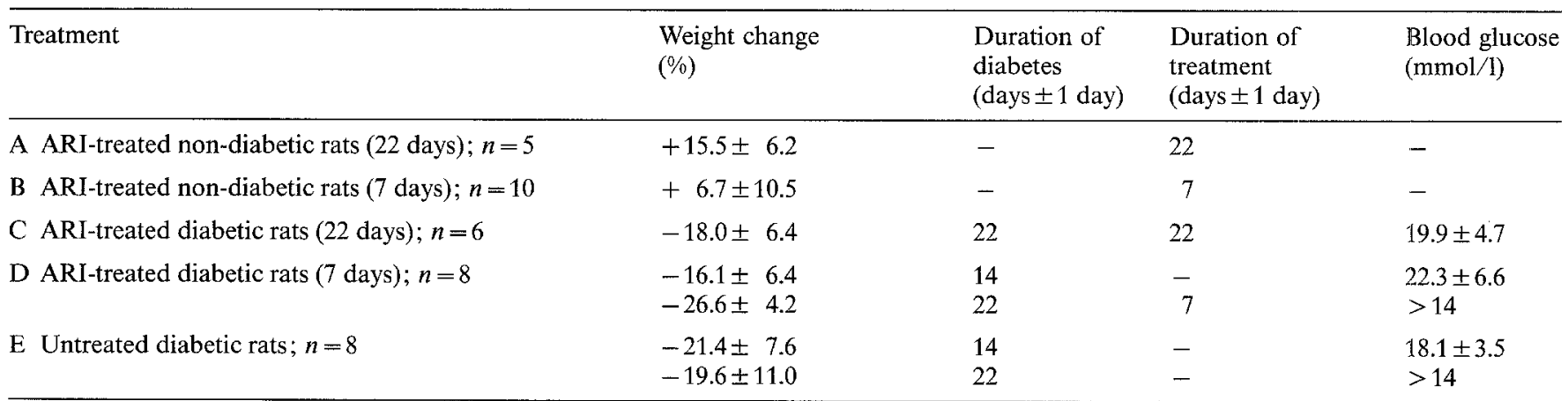

Body weights are mean \pm SD of the $\%$ change between weights at 14 days or 22 days after induction of diabetes, or injection of citrate buffer as indicated, and weights prior to treatment. Blood glucose concentrations are mean \pm SD. The apparent change in weight in group D between 14 and 22 days is not significantly different from that in group $\mathrm{E}$ 
Table 2. Changes in nerve sorbitol and myo-inositol

\begin{tabular}{lll}
\hline Treatment & $\begin{array}{l}\text { Sorbitol } \\
\text { (nmol } / \mathrm{mg} \\
\text { wet weight) }\end{array}$ & $\begin{array}{l}\text { Myo-inositol } \\
\text { (nmol } / \mathrm{mg} \\
\text { wet weight) }\end{array}$ \\
\hline $\begin{array}{l}\text { A. ARI-treated non-diabetic rats } \\
\text { (22 days); } n=5\end{array}$ & $0.15 \pm 0.12^{\mathrm{a}}$ & $4.17 \pm 1.32^{\mathrm{b}}$ \\
$\begin{array}{l}\text { C. ARI-treated diabetic rats } \\
\quad \text { (22 days); } n=6\end{array}$ & $0.33 \pm 0.20^{\mathrm{a}}$ & $2.98 \pm 0.42$ \\
E. Untreated diabetic rats; $n=8$ & $2.87 \pm 0.87$ & $2.75 \pm 0.81$ \\
\hline
\end{tabular}

Values for nerve myo-inositol and sorbitol are means \pm SD measured 22 days after induction of diabetes or injection of citrate buffer, in all groups. Where indicated, values were significantly different from those in the diabetic group at the ${ }^{\mathrm{a}} p<0.001$ and ${ }^{\mathrm{b}} p<0.05$ level

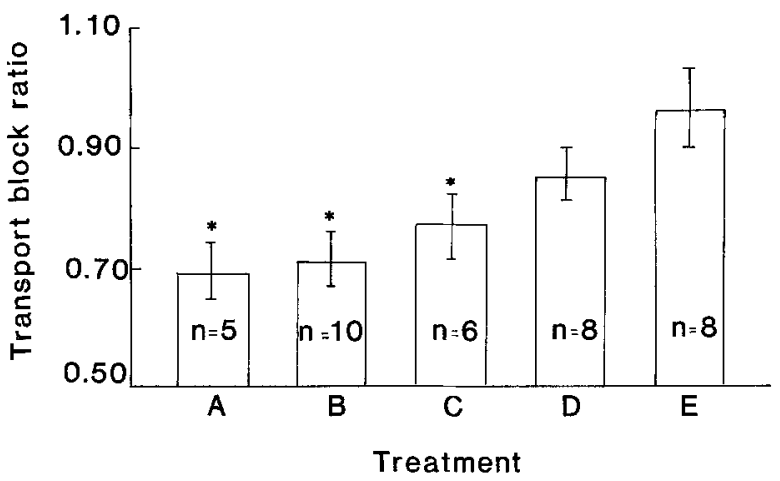

Fig. 1. Transport block ratio in control and diabetic nerves compressed at $30 \mathrm{mmHg}$ for $3 \mathrm{~h}$. Each bar is mean \pm SEM of 5 to $10 \mathrm{ex}$ periments. $A=$ non diabetic rats treated with ARI for 22 days. $\mathrm{B}=$ non-diabetic rats treated with $\mathrm{ARI}$ for 7 days. $\mathrm{C}=$ diabetic rats treated with ARI for 22 days. $\mathrm{D}=$ diabetic rats treated with ARI for 7 days. $E=$ untreated diabetic rats. Groups marked* are significantly different from the group of diabetic rats at the $p<0.05$ level

\section{Nerve content of sorbitol and myo-inositol}

The sciatic nerve content of sorbitol and myo-inositol for untreated diabetic rats and after 3 weeks of treatment of control rats and diabetic rats with ARI are summarised in Table 2. In untreated diabetic rats there was an approximately 10 -fold accumulation of sorbitol and around 40\% reduction of myo-inositol content as compared to treated controls. Treatment of diabetic rats with ARI maintained the content of sorbitol to near normal levels but did not prevent the myo-inositol deficit. This contrasts with other reports in which 'Statil' and other ARIs have been shown to protect against myo-inositol depletion $[13,19]$.

\section{Inhibition of fast axonal transport}

The transport block ratios in treated control rats, treated diabetic rats and untreated diabetic rats are summarised in Figure 1. Compression of the sciatic nerve at $30 \mathrm{mmHg}$ for $3 \mathrm{~h}$ induced a slight accumulation of fast axonally transported proteins at the site of compression in control rats treated with the ARI. The transport block ratio (TBR) was $0.71 \pm 0.17(n=10)$ in rats treated with ARI for 7 days and $0.69 \pm 0.08(n=5)$ in rats treated with ARI for 22 days. These values are not different from previously published data on untreated controls $(0.67 \pm 0.16 ; n=7)$ [9]. Compression, at the same pressure and for the same duration, of the sciatic nerve in untreated diabetic rats produced a marked inhibition of fast transport. In nerves of diabetic rats the transport block ratio was increased to $0.96 \pm 0.24$ $(n=8)$, which is not different from previously published values for untreated diabetic rats $(1.01 \pm 0.35 ; n=7)$ [9]. The differences between treated controls and untreated diabetic rats were statistically significant. Compression at $30 \mathrm{mmHg}$ for $3 \mathrm{~h}$ induced a less pronounced inhibition of fast transport in the sciatic nerve of treated diabetic rats as compared to untreated diabetic rats. The value for diabetic rats treated for 7 days was $0.85 \pm 0.11(n=8)$ and for diabetic rats treated for 22 days was $0.77 \pm 0.12(n=6)$. The latter was significantly different from the value for untreated diabetic rats; the difference in the values was 0.19 (95\% confidence limits: 0.01 to 0.37 ).

The inhibition of fast axonal transport in the untreated diabetic rats was substantial but not complete; the transport block ratio lay approximately halfway between that in uncompressed nerves (around 0.5) and that in nerves which have been ligated (around 1.5), in which the distal part of all the axons will degenerate [9].

\section{Discussion}

The present study shows that local compression of rat sciatic nerves at $30 \mathrm{mmHg}$ for $3 \mathrm{~h}$ induces a less pronounced accumulation of transported radioactive proteins in diabetic rats treated with an aldose reductase inhibitor than in untreated diabetic rats.

While only the rats treated with the ARI for the total duration of diabetes exhibited a significant prevention of the increased susceptibility to compression, the mean values of the TBR in the rats treated for 7 days after two weeks of diabetes was also less than that for untreated diabetic rats, suggesting that the ARI may be able to reverse as well as prevent the lesion, although a prolonged treatment period may be necessary to provide maximal benefit.

In the sorbitol pathway, which is present in many tissues including nerve, glucose is converted to sorbitol via aldose reductase; sorbitol dehydrogenase then converts sorbitol to fructose [20]. Nerve tissue can take up glucose in the absence of insulin and the sugar alcohols sorbitol and fructose cannot diffuse away from their site of synthesis. The accumulation of the sugar alcohols in diabetic nerves may generate osmotic fluid shifts [21] and the endoneurial space may expand due to an increased water content $[10,11]$. The increased water content in diabetic nerves may affect the nerves by at least two different mechanisms either of which could increase the susceptibility to compression. First, 
the nerve fibres have to take up more of the applied pressure than do axons in normal peripheral nerves where individual nerve fibres are protected by surrounding connective tissue giving structural support. Second, $\mathrm{O}_{2}$ supply to axons may be compromised either by an increase in the diffusion distance of oxygen from endoneurial capillaries to axons through expansion of the endoneurial space, or by an effect on capillary blood flow. Endoneurial hypoxia has been shown to occur in diabetic neuropathy [22] and in galactose neuropathy in which a more pronounced endoneurial oedema is found [23-25]. An increased susceptibility to compression has been assumed to occur in galactose neuropathy [26].

Potent inhibitors of aldose reductase have become available during the last few years [27]. These inhibitors can completely prevent or reverse the accumulation of sorbitol and markedly reduce the accumulation of fructose in rat sciatic nerves as well as prevent the depletion of myo-inositol. This may lead to prevention or reversal of defects in axonal transport, and nerve conduction velocity deficit $[13,17,19,28-31]$. It can also decrease the water content in diabetic nerves as indicated by measurement of wet weight/unit length of nerve [11, 32]. Treatment of galactose-intoxicated rats with an aldose reductase inhibitor restores to normal levels the elevated sodium concentration, the increased water content and interstitial fluid pressure characteristic of galactose neuropathy [33, 34].

In the present study, the elevated nerve content of sorbitol was also reduced by administration of Statil to the diabetic rats, although no significant restoration of myo-inositol was detected.

Since our experimental protocol did not include a diabetic control group treated with insulin it has to be emphasised that the slight increase in sorbitol levels, the increased transport block ratio as well as the fall in myo-inositol levels may have been due to extrapancreatic effects of streptozotocin (group C compared to group A).

The results indicate that increased susceptibility to nerve compression may be partly prevented by administration of an aldose reductase inhibitor for the duration of the diabetic state and, therefore, that the cause of increased susceptibility to compression is related to the increased content of nerve polyols.

The role of an impairment of fast axonal transport in nerve compression disorders is at present speculative; other features such as focal demyelination and axon dwindling need also to be taken into account. With regard to the latter, which is more readily equated with changes in slow transport, our own results indicate that compression levels which affect fast axonal transport similarly disrupt slow [35]. We would therefore predict that in the experiments described here, the inhibition of fast transport serves as a measure of effects on axonal transport in general. Aldose reductase inhibitors may reduce the impact which impairment of axonal transport has on the course of nerve compression disorders, such as carpal tunnel syndrome in diabetic patients.

Acknowledgements. The work was supported by grants from ICI Pharmaceuticals (UK), the Swedish Medical Research Council (5188), the Göteborg Medical Society, the Swedish Society of Medicine and the Swedish Society for Medical Research. We are grateful to J.Mahon and D. Trafford for technical assistance, to C. West for invaluable advice on statistical analysis, and to D. Mirrlees for analysis of polyols. D. Archer is a M. R. C. scholar.

\section{References}

1. Mulder DW, Lambert EH, Bastrom JA, Sprague RG (1961) The neuropathies associated with diabetes mellitus. A clinical and electromyographic study of 103 unselected diabetic patients. Neurology 11:275-284

2. Phalen GS (1966) The carpal-tunnel syndrome. Seventeen years' experience in diagnosis and treatment of six hundred fifty-four hands. J Bone Joint Surg 48 A: 211-228

3. Phalen GS (1972) The carpal-tunnel syndrome. Clinical evaluation of 598 hands. Clin Orthop Rel Res 83: 29-40

4. Brown MJ, Asbury AK (1984) Diabetic neuropathy. Ann Neurol 15: $2-12$

5. Comi G, Lozza L, Galardi G, Ghilardi MF, Medaglini S, Canal $\mathrm{N}$ (1985) Presence of carpal tunnel syndrome in diabetics: effect of age, sex, diabetes duration and polyneuropathy. Acta Diabetol Latina 22: 259-262

6. Brown MJ, Sumner AJ, Greene DA, Diamond SM, Asbury AK (1980) Distal neuropathy in experimental diabetes mellitus. Ann Neurol 8: 168-178

7. Moore SA, Peterson RG, Felten DL, O'Connor BL (1981) Glycogen accumulation in tibial nerves of experimentally diabetic and aging control rats. J Neurol Sci 52: 289-303

8. Moore SA, Peterson RG, Felten DL, O'Connor BL (1982) Ultrastructural axonal pathology in experimentally diabetic and aging control rats. Brain Res Bull 8: 317-323

9. Dahlin LB, Meiri KF, McLean WG, Rydevik B, Sjöstrand J (1986) Effects of nerve compression on fast axonal transport in streptozotocin-induced diabetes mellitus. Diabetologia 29: 181-185

10. Jakobsen J (1978) Peripheral nerves in early experimental diabetes. Expansion of the endoneurial space as a cause of increased water content. Diabetologia 14: 113-119

11. Tomlinson DR, Sidenius P, Larsen JR (1986) Slow component-a of axonal transport, nerve myo-inositol, and aldose reductase in. hibition in streptozotocin-diabetic rats. Diabetes 35: 398-402

12. Tomlinson DR, Moriarty RJ, Mayer JH (1984) Prevention and reversal of defective axonal transport and motor nerve conduction velocity in rats with experimental diabetes by treatment with the aldose reductase inhibitor Sorbinil. Diabetes 33: 470-476

13. Tomlinson DR, Townsend J, Fretten P (1985) Prevention of defective axonal transport in streptozotocin-diabetic rats by treatment with "Statil" (ICI 128436), an aldose reductase inhibitor. Diabetes 34: 970-972

14. Willars GB, Tomlinson DR, Robinson JP (1986) Studies of Sorbinil on axonal transport in streptozotocin-diabetic rats. Metabolism 35 [Suppl 1]: $66-70$

15. Meiri KF, McLean WG (1982) Axonal transport of protein in motor fibres of experimentally diabetic rats - fast anterograde transport. Brain Res 238: 77-88

16. Dahlin LB, Rydevik B, McLean WG, Sjöstrand J (1984) Changes in fast axonal transport during experimental nerve compression at low pressures. Exp Neurol 84: 29-36

17. Stribling D, Mirrlees DJ, Harrison HE, Earl DCN (1985) Properties of 128436, a novel aldose reductase inhibitor and its effects on diabetic complications in the rat. Metabolism 34: 336-44

18. SPSS Inc (1983) SPSSX. McGraw Hill, New York, pp 458-9 
19. Greene DA and Lattimer SA (1984) Action of Sorbinil in diabetic peripheral nerve. Relationship of polyol (Sorbitol) pathway inhibition to a myoinositol-mediated defect in sodium-potassium ATPase activity. Diabetes 33: 712-716

20. Gabbay KH, Merola LO, Field RA (1966) Sorbitol pathway: presence in nerve and cord with substrate accumulation in diabetes. Science 151: 209-210

21. Gabbay KH (1975) Hyperglycemia, polyol metabolism, and complications of diabetes mellitus. Ann Rev Med 16: 521-536

22. Tuck RR, Schmelzer JD, Low PA (1984) Endoneurial blood flow and oxygen tension in the sciatic nerves of rats with experimental diabetic neuropathy. Brain 107: 935-950

23. Low PA, Nukada H, Schmelzer JD, Tuck RR, Dyck PJ (1985) Endoneurial oxygen tension and radial topography in nerve edema. Brain Res 341: 147-154

24. Myers RR, Costello ML, Powell HC (1979) Increased endoneurial fluid pressure in galactose neuropathy. Muscle Nerve 2: 299-303

25. Myers RR, Powell HC (1984) Galactose neuropathy; impact of chronic endoneurial edema on nerve blood flow. Ann Neurol 16: 587-594

26. Low PA, Dyck PJ, Schmelzer JD (1982) Chronic elevation of endoneurial fluid pressure is associated with low-grade fiber pathology. Muscle Nerve 5: 162-165

27. Kador PF, Robison WG Jr, Kinoshita JH (1985) The pharmacology of aldose reductase inhibitors. Ann Rev Pharm Tox: $691-714$

28. Tomlinson DR, Holmes PR, Mayer JH (1982) Reversal, by treatment with an aldose reductase inhibitor, of impaired axonal transport and motor nerve conduction velocity in experimental diabetes mellitus. Neurosci Lett 31: 189-193

29. Mayer JH, Tomlinson DR (1983) Prevention of defects of axonal transport and nerve conduction velocity by oral administration of myoinositol or an aldose reductase inhibitor in streptozotocindiabetic rats. Diabetologia 25: 433-438

30. Tomlinson DR and Mayer JH (1984) Defects of axonal transport in diabetes mellitus - a possible contribution to the aetiology of diabetic neuropathy. J Auton Pharmacol 4: 59-72

31. Yue DK, Hanwell MA, Satchell PM, Turtle JR (1982) The effect of aldose reductase inhibition on motor nerve conduction velocity in diabetic rats. Diabetes 31: 789-794

32. Yue DK, Hanwell MA, Satchell PM, Handelsman DJ, Turtle JR (1984) The effects of aldose reductase inhibition on nerve sorbitol and myoinositol concentrations in diabetic and galactosemic rats. Metabolism 33: 1119-1122

33. Mizisin AP, Myers RR, Powell HC (1986) Endoneurial sodium accumulation in galactosemic rat nerves. Muscle Nerve 9: 440-444

34. Mizisin AP, Powell HC, Myers RR (1986) Edema and increased endonurial sodium in galactose neuropathy. Reversal with an aldose reductase inhibitor. J Neurol Sci 74: 35-43

35. Dahlin LB, McLean WG (1986) Effects of graded experimental nerve compression on slow and fast axonal transport in rabbit vagus nerve. J Neurol Sci 72: 19-30

Received: 17 December 1986

and in revised form: 30 April 1987

Dr. W.G. McLean

Department of Pharmacology and Therapeutics

PO Box 147

Liverpool L69 3BX

UK 